\title{
Leveraging Knowledge Sharing and Innovation Towards Resilient Competitive Advantage:
}

\author{
Insight from the Leaders
}

\author{
I Wayan Edi Arsawan ${ }^{1, *}$, Putu Adriani Prayustika ${ }^{1}$, I Gusti Ketut Gede ${ }^{1}$, Ni Made Kariati ${ }^{1}$, Putu Wijaya Sunu ${ }^{2}$, I \\ Nyoman Eddy Indrayana ${ }^{2}$ \\ ${ }^{1}$ Department of Business Administration, ${ }^{2}$ Department of Mechanical Engineering \\ Politeknik Negeri Bali \\ Badung, Indonesia \\ *wayanediarsawan@pnb.ac.id, adrianiprayustika@pnb.ac.id,igkgede@pnb.ac.id,dekariati@pnb.ac.id,
}

\begin{abstract}
The role of knowledge sharing has been tested and explored in various empirical studies related to organizations. However, research that explores knowledge sharing in building innovation and explores the role of innovation comprehensively is still rare in the SME sector. The purpose of this study was to examine and explain the relationship between knowledge sharing in building innovation to build a resilient competitive advantage. This study used a quantitative design involving 118 respondents from 59 sample frames consisting of management levels, namely assistant and managers of SMEs Export in Bali Province, Indonesia. The questionnaire uses a Likert scale, and the data is processed with SmartPLS 3.0 software. The results showed that knowledge sharing has a significant effect on innovation and resilient competitive advantage and innovation as mediator. Theoretically, this research provides insight into the body of knowledge. Practically, research is concerned with the recognition of intellectual capital in the organization. The limitations of the study are discussed in the paper.
\end{abstract}

Keywords-knowledge sharing, innovation, SEM, business performance, resilient competitive advantage

\section{INTRODUCTION}

The competitive advantage has caught the attention of many researchers around the world, has been tested involving various variables, but cannot be fully explained clearly. Competitive advantage plays a crucial role in the sustainability and success of SMEs by innovating [1,2], especially innovative entrepreneurship, technological changes, and market uncertainty [3]. The failure rate of SMEs is high in both developing and developed countries [1].

Building a competitive advantage through optimizing knowledge sharing contribution as the key factor of innovation [4,5], and crucial driver to creating values [6,7], especially for small and medium enterprises [8]. Although most empirical research has been conducted, the SME sector still needs to be investigated [9]. Thus, the researchers point to a lack of studies that comprehensively explore innovation in the SME sector.
An organization has a competitive advantage when implementing a strategy of value creation than competitors [10] and cannot duplicate strategies [11]. Unique resource ownership causes companies to outperform competitors, as the main source of resilient competitive advantage [12].

This study tries to close the research gap, namely; first, a resilient competitive advantage cannot be explained in a conceptual framework [13]. Second, innovation research in SMEs is still rarely conducted and must be carried out in a sustainable manner $[14,15]$. Third, the research on innovation in the SME sector [16] is to develop and understand innovation both theoretical and applied [17]. Thus, this research need attention to understand a better analysis in for Indonesian SMEs.

\section{LITERATURE REVIEWS}

\section{A. Knowledge Sharing}

Knowledge management dimensions are important is knowledge sharing which is referred to as a complex activity [18] which generates new ideas [19] in increasing knowledge assets. The importance of sharing knowledge is expanding networks, opportunities, and enhancing processes and improve both products and services [20]. Knowledge sharing will be a success with the involvement of individuals that increase creativity and accelerate innovation [21].

\section{B. Innovation}

Many scholars said that innovation is a key instrument for facing an uncertain business environment [7] that recognize innovation is very crucial in a complex environment $[22,23]$ and important in determining sustainability role in success and survival [24].

\section{Resilient Competitive Advantage (RCA)}

A resilient competitive advantage occurs when other companies are unable to replicate the competitive advantage. 
Organizations are expected to focus on different strategy, enhance service delivery, and hiring high quality manpower [18] to achieve performance [25]. Resilient competitive advantage achieved through effective strategy [26] namely: leadership, organizational culture, team-based structure, and human capital and control management [13].

\section{Hypothesis Development}

Knowledge management builds an innovation in shaping the business innovation model and capability [27] and competitive advantage [28]. Specifically, knowledge sharing builds a strong relationship with innovation [21] and has a significant effect on innovation [29-31]. Based on this, the hypothesis can be formulated as follows:

- H1: Knowledge sharing has a significant effect on innovation.

Knowledge sharing forms a new knowledge [31,32] increasing knowledge sources [33] through collaboration and creation [34] and has a significant positive effect on competitive advantage [18] because knowledge-based assets are key success of resilient competitive advantage [28].

- H2: Knowledge sharing has a significant effect on resilient competitive advantage.

Innovation develop of new products, processes, and added value [35]. Competitive advantage refers that organization has resources and capabilities [36] capacity to adapt, respond, and detect opportunities [37] and react successfully to change [38]; [11] both in the technical and non-technical [25]. Based on this, the hypothesis can be formulated as follows. Based on this, the hypothesis can be formulated as follows:

- H3: Innovation has a significant effect on resilient competitive advantage

\section{Methodology}

\section{A. Data Collection and Sampling}

The population in this study were 69 export SMEs in Bali, Indonesia. Furthermore, the sample frame was selected by the simple random sampling method [39], were 59 enterprises and 2 respondents were sought each to be asked to fill out the questionnaire. The total number of respondents was 118 respondents. Unit analysis are assistant managers and managers.

\section{B. Measures}

All measurements were adopted and modified from previous studies where the construct was designed using a selfassessment report with a Likert scale 1-5 approach (1-strongly disagree to 5-strongly agree).

Knowledge sharing is measured by four indicators, namely socialization, externalization, combination, and internalization which are adopted from previous research [29,30,33,40].
Innovation is measured by five indicators, namely organizational culture, product innovation, innovation process, innovation management, and innovation objectives $[4,15,16]$.

Resilient competitive advantage is measured by seven indicators, namely innovation practices, service delivery systems, growth and performance, market share [10,34,41], value, rareness, and imperfectly non-imitable $[1,25]$

\section{RESULTS AND DISCUSSION}

The research data were analysed with PLS-3.0 software through evaluation of the outer model and testing of the inner model.

\section{A. Outer Model Measurement}

Measuring reliability in present study uses three measurement methods, namely convergent validity, discriminant validity, and composite reliability. The results of convergent validity use the outer loading value of each indicator is between 0.529-0.973 and meets the requirements. Discriminant validity with the AVE value is greater than 0.50 . All outer loading values are above 0.50 which indicates all indicators have good discriminant validity.

\section{B. Inner Model Measurement}

Testing inner model uses three approaches, namely, the R2 analysis, Goodness of Fit (GoF). The calculation of Q2 and Goodness of Fit (GoF) uses the R-square coefficient (R2) to shows the model feasibility. The R2 value of 0.67 classified as a strong model, 0.33 is classified as a moderate model and 0.19 is classified as a weak model.

TABLE I. $\quad \mathrm{R}^{2}$ AND $\mathrm{R}^{2}$ ADJUSTED

\begin{tabular}{|l|c|c|c|}
\hline \multirow{2}{*}{\multicolumn{1}{|c|}{ Latent }} & \multicolumn{3}{|c|}{ Coefficients } \\
\cline { 2 - 4 } & Remarks & $\boldsymbol{R 2}$ & Adj $\boldsymbol{R} 2$ \\
\hline Innovation & Y1 & 0,651 & 0,649 \\
\hline Resilient Competitive Adv & Y2 & 0,743 & 0,739 \\
\hline Average & & 0,697 & 0,694 \\
\hline
\end{tabular}

Based on Table 1, the value of R2 innovation is 0.651 , RSC is 0.743 so that the $\mathrm{R} 2$ concluded as strong model. The average value of 0.697 means that the relationship model is explained by 69.7 percent, while the remaining 30.3 percent is explained by other variations outside the model.

The next step is to test the Q Square Predictive Relevance (Q2) by measuring how well the model observations are:

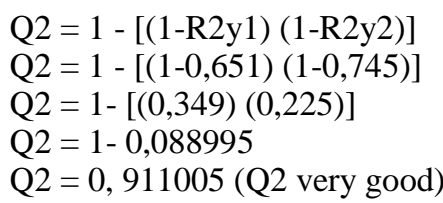

The result of Q2 shows the value of 0.911005 means that the observation model is very good, namely $91.10 \%$ the relationship between variables can be explained by the model 
while the remaining $8.90 \%$ is another factor that is not included in the research model. The next step is calculating the GoF.

$$
\begin{aligned}
& \text { GoF }=\sqrt{ } \text { com } \times \mathrm{R} 2 \\
& =\sqrt{ } 0,673 \times 0,697 \\
& =\sqrt{ } 0,469081 \\
& =0,68489
\end{aligned}
$$

The GoF results show a value of 0.68489 which is close to 1 (one), which means that the predictive model is very fit, which means that the accuracy of the measurement of the model is very good. Furthermore, testing the effect size (f2).

\section{Hypothesis Testing}

After the outer and inner model tests, the next step is hypothesis testing which is carried out in two stages by testing the direct and indirect effect. In the output path coefficient, as shown in Table 2, the direct relationship between variables is presented by looking at the value of the parameter coefficient through the original sample.

TABLE II. COEFFICIENTS OF VARIABLES

\begin{tabular}{|c|c|c|c|c|c|c|}
\hline Construct & $\begin{array}{c}\text { Original Sample } \\
(\mathbf{O})\end{array}$ & $\begin{array}{c}\text { Sample Mean } \\
(\mathbf{M})\end{array}$ & $\begin{array}{c}\text { Standard Deviation } \\
(\text { STDEV) }\end{array}$ & $\begin{array}{c}\text { T Statistics } \\
(\mid \mathbf{O} / \text { STDEV })\end{array}$ & P Values & Decision \\
\hline KS $\rightarrow$ IC & 0,803 & 0,810 & 0,014 & 14,000 & 0,000 & Supported \\
\hline KS $\rightarrow$ RCA & 0,771 & 0,704 & 0,061 & 8,969 & 0,000 & Supported \\
\hline IC $\rightarrow$ RCA & 0,358 & 0,361 & 0,089 & 2,704 & 0,000 & Supported \\
\hline
\end{tabular}

KS: knowledge sharing, IC: innovation, RCA: resilient competitive advantage

In Table 2, information is presented about the direct relationship between variables. The path coefficient of knowledge sharing, and innovation is 14,000> 1.96 which means significant and hypothesis 1 is accepted. The results of this study concluded that knowledge sharing plays an important role in building innovation [29,36] and realizing innovation [41]. The results of this study also refute the research results [21] that knowledge sharing does not contribute significantly to innovation.

The coefficient of the relationship between knowledge sharing and RCA is 8,969> 1.96 which means significant and hypothesis 2 is accepted. This research is concluded that knowledge sharing is a source of competitive advantage $[18,32]$.

The path coefficient between innovation and resilient competitive advantage is $2.704>1.96$ which means significant and hypothesis 3 is accepted. The results of the study found that SMEs can take advantage of innovation to increase a resilient competitive advantage [42]. This means that export SMEs must be creative and innovative facing global market $[41,43]$.

TABLE III. MEDIATING EFFECT TEST

\begin{tabular}{|c|c|c|c|c|c|c|c|}
\hline Mediator* & $\begin{array}{c}\text { Independent Variable- } \\
\text { Mediator }\end{array}$ & $\begin{array}{c}\text { Mediator- Dependent } \\
\text { Variable }\end{array}$ & Direct & Indirect & Total effect & $\begin{array}{c}\text { VAF } \\
(\%)\end{array}$ & Decision \\
\hline KS-In-RCA & 0,803 & 0.368 & 0.771 & 0.623841 & 1.002953 & 0.622073 & Partial mediation \\
\hline
\end{tabular}

*KS: knowledge sharing, IC: innovation, RCA: resilient competitive advantage, VAF: Variance Accounted Fo

The next step is to test innovation as the mediating variable (see Table 3). Based on the VAF criteria which is VAF $<0.20$ (no mediation), $0.20-0.80$ (partial mediation) and $>0.80$ (full mediation) [44]. We calculated Variance Accounted For (VAF). The present study tested only one path mediator, it can be concluded that innovation partially mediates the relationship between $\mathrm{KS}$ and RCA where the VAF value is equal to 62.22 percent.

\section{CONCLUSION}

This study succeeded in closing three literature gaps, namely offering knowledge and conceptualizing new research models, that building sustainable competitive advantage cannot be explained by one model. Second, innovation is very important for SMEs and SME managers to need to innovate to be able to compete with established companies, and third, competitive advantage associated with knowledge and innovation is still rare, especially in developing countries and
SMEs in Indonesia must have high innovation to successfully maintain a formidable competitive advantage.

\section{REFERENCES}

[1] M. Anwar, A.U. Rehman, and S.Z.A. Shah, "Networking and new venture's performance: the mediating role of competitive advantage," International Journal of Emerging Markets, vol. 13, no. 5, pp. 998-1025, 2018

[2] T. Anning-Dorson, "Innovation and competitive advantage creation: The role of organizational leadership in service firms from emerging markets," International Marketing Review, vol. 35, no. 4, pp. 580-600, 2018 .

[3] B.D.L. Hoz Rosales, J.A. Camacho Ballesta, and I. Torres, "Effects of innovative entrepreneurship and the information society on social progress: an international analysis," Digibug, 2019

[4] R. Magnier-Watanabe and Senoo, "Congruent knowledge management behaviors as discriminate sources of competitive advantage," Journal of Workplace Learning, vol. 21, no. 2, pp. 109-124, 2009. 
[5] F. Ahmad, "Knowledge sharing in a non-native language context: Challenges and strategies," Journal of Information Science, vol. 44, no. 2, pp. 248-264, 2018.

[6] A. Exposito and J.A. Sanchis-llopis, "Innovation and business performance for Spanish SMEs: New evidence from a multidimensional approach," International Small Business Journal, vol. 36, no. 8, pp. 911-931, 2018

[7] M. Aboramadan, B. Albashiti, H. Alharazin, and S. Zaidoune, "Organizational culture, innovation and performance: a study from a non-western context”, Journal of Management Development, 2019.

[8] R.V.D. Jordão, J. Novas, and V. Gupta, "The role of knowledge-based networks in the intellectual capital and organizational performance of small and medium-sized enterprises," Kybernetes, 2019.

[9] W. Ben Arfi, R. Enstroem, J.M. Sahut, and L. Hikkerova, "The significance of knowledge sharing platforms for open innovation success: A tale of two companies in the dairy industry," J. Organ. Chang. Manag., vol. 32, no. 5, pp. 496-516, 2019.

[10] N.R. Zainol and A. Al Mamun, "Entrepreneurial competency, competitive advantage and performance of informal women microentrepreneurs in Kelantan, Malaysia," J. Enterprising Communities People Places Glob. Econ., 2018.

[11] T. Anning-Dorson and M.B. Nyamekye, "Be flexible: turning innovativeness into competitive advantage in hospitality firms," Int. J. Contemp. Hosp. Manag., 2020.

[12] C.-H. Wang, "How organizational green culture influences green performance and competitive advantage," J. Manuf. Technol. Manag., 2019.

[13] I. Gutiérrez-Martínez and F. Duhamel, "Translating sustainability into competitive advantage: the case of Mexico's hospitality industry," Corp. Gov. Int. J. Bus. Soc., 2019.

[14] D. Kafetzopoulos, K. Gotzamani, and D. Skalkos, "The relationship between EFQM enablers and business performance,” J. Manuf. Technol. Manag., 2019

[15] M. Dabić, J. Lažnjak, D. Smallbone, and J. Švarc, "Intellectual capital, organisational climate, innovation culture, and SME performance: Evidence from Croatia,” J. Small Bus. Enterp. Dev., 2019.

[16] H. Hanifah, H.A. Halim, N.H. Ahmad, and A. Vafaei-Zadeh, "Emanating the key factors of innovation performance: leveraging on the innovation culture among SMEs in Malaysia," J. Asia Bus. Stud., 2019.

[17] H. Hanifah, H.A. Halim, N.H. Ahmad, and A. Vafaei-Zadeh, "Can internal factors improve innovation performance via innovation culture in SMEs?," Benchmarking An Int. J., 2019.

[18] R. Eidizadeh, R. Salehzadeh, and A.C. Esfahani, "Analysing the role of business intelligence, knowledge sharing and organisational innovation on gaining competitive advantage,” J. Work. Learn., 2017.

[19] B.Y. Obeidat, M.M. Al-Suradi, and A. Tarhini, "The impact of knowledge management on innovation," Manag. Res. Rev., 2016.

[20] M.O. Steffen, M. Oliveira, and A.R. Balle, "Knowledge sharing among companies in a science and technology park," Bus. Inf. Rev., vol. 34, no. 2, pp. 101-108, 2017.

[21] E.K. Teixeira, M. Oliveira, and C. Curado, "Linking knowledge management processes to innovation," Manag. Res. Rev., 2019.

[22] Z. Wang, P.N. Sharma, and J. Cao, "From knowledge sharing to firm performance: A predictive model comparison,” J. Bus. Res., vol. 69, no. 10, pp. 4650-4658, 2016.

[23] Z. Wang, N. Wang, J. Cao, and X. Ye, "The impact of intellectual capital-knowledge management strategy fit on firm performance," Manag. Decis., 2016.

[24] P. Ghasemzadeh, J.A. Nazari, M. Farzaneh, and G. Mehralian, "Moderating role of innovation culture in the relationship between organizational learning and innovation performance," Learn. Organ., 2019.
[25] S.A. Bhat and M.A. Darzi, "Service, People and Customer Orientation: A Capability View to CRM and Sustainable Competitive Advantage,' Vision, vol. 22, no. 2, pp. 163-173, 2018.

[26] G.K. Amoako, “A conceptual framework: Corporate environmental management activities and sustainable competitive advantage," Manag. Environ. Qual. An Int. J., vol. 31, no. 2, pp. 331-347, 2020.

[27] S. Wichitsathian and D. Nakruang, "Knowledge integration capability and entrepreneurial orientation: case of Pakthongchai Silk Groups Residing," Entrep. Sustain. Issues, vol. 7, no. 2, pp. 977-989, 2019.

[28] M. Bashir and R. Farooq, "The synergetic effect of knowledge management and business model innovation on firm competence," Int. J. Innov. Sci., 2019.

[29] S.S. Boroujerdi, K. Hasani, and V. Delshab, "Investigating the influence of knowledge management on organizational innovation in higher educational institutions," Kybernetes, 2019.

[30] S. Berraies, "Effect of middle managers' cultural intelligence on firms' innovation performance," Pers. Rev., 2019.

[31] J. Peters, K. Snowden, M.J. Lin, and C. Chen, "Integration and knowledge sharing: transforming to long-term competitive advantage," Int. J. Organ. Anal., 2008.

[32] J. Connell and R. Voola, "Knowledge integration and competitiveness: longitudinal study of an industry cluster," J. Knowl. Manag., 2013.

[33] Ratnawati, B.E. Soetjipto, F.D. Murwani, and H. Wahyono, "The Role of SMEs' Innovation and Learning Orientation in Mediating the Effect of CSR Programme on SMEs' Performance and Competitive Advantage," Glob. Bus. Rev., vol. 19, no. 3_suppl, pp. S21-S38, 2018.

[34] O.F. Ayanbode and W.E. Nwagwu, "Collaborative technologies and knowledge management in psychiatric hospitals in South West Nigeria," Inf. Dev., p. $0266666919895563,2020$.

[35] Y. Chen, Y. Wang, S. Nevo, J. Benitez-Amado, and G. Kou, "IT capabilities and product innovation performance: The roles of corporate entrepreneurship and competitive intensity," Inf. Manag., vol. 52, no. 6, pp. 643-657, 2015.

[36] A. Iqbal, F. Latif, F. Marimon, U.F. Sahibzada, and S. Hussain, "From knowledge management to organizational performance," J. Enterp. Inf. Manag., 2019.

[37] J.M. Kneipp, C.M. Gomes, R.S. Bichueti, K. Frizzo, and A.P. Perlin, "Sustainable innovation practices and their relationship with the performance of industrial companies," Rev. Gestão, 2019.

[38] P. Chatzoglou and D. Chatzoudes, "The role of innovation in building competitive advantages: an empirical investigation," Eur. J. Innov. Manag., 2018.

[39] R.V Krejcie and D.W. Morgan, "Determining sample size for research activities,” Educ. Psychol. Meas., vol. 30, no. 3, pp. 607-610, 1970.

[40] A. Julpisit and V. Esichaikul, "A collaborative system to improve knowledge sharing in scientific research projects," Inf. Dev., vol. 35, no. 4, pp. 624-638, 2019.

[41] A.K. Singh, J. Verma, and R. Verma, "Understanding Role of Marketorientated IT Competence and Knowledge Sharing Mechanism in Gaining Competitive Advantage," Glob. Bus. Rev., vol. 21, no. 2, pp. 418-435, 2020

[42] H.-E. Lin, I.-C. Hsu, A.W. Hsu, and H.-M. Chung, "Creating competitive advantages: Interactions between ambidextrous diversification strategy and contextual factors from a dynamic capability perspective,” Technol. Forecast. Soc. Change, vol. 154, p. 119952, 2020.

[43] J.F. Hair Jr, G.T.M. Hult, C. Ringle, and M. Sarstedt, A primer on partial least squares structural equation modeling (PLS-SEM). Sage publications, 2016.

[44] A. Mitra, S. S. Gaur, and E. Giacosa, "Combining organizational change management and organizational ambidexterity using data transformation,” Manag. Decis., 2019. 